Please do not remove this page

RMIT

UNIVERSITY

\title{
Social capital and cannabis supply
}

Scott, John; Grigg, Jodie; Barratt, Monica; Lenton, Simon

https://researchrepository.rmit.edu.au/esploro/outputs/9921860836101341/filesAndLinks?institution=61RMIT_INST\&index=null

Scott, J., Grigg, J., Barratt, M., \& Lenton, S. (2017). Social capital and cannabis supply. Journal of Sociology, 53(2), 382-397. https://doi.org/10.1177/1440783316688342

Document Version: Accepted Manuscript

Published Version: https://doi.org/10.1177/1440783316688342

Repository homepage: https://researchrepository.rmit.edu.au

CC BY-NC-ND V4.0

(C) The Author(s) 2017

Downloaded On 2023/04/26 16:19:49 +1000

Please do not remove this page 


\section{SOCIAL CAPITAL AND CANNABIS SUPPLY}

\section{Introduction}

This paper examines the concept of social supply in relation to Australian cannabis markets. Cannabis is the most widely used illicit drug in Australia (Australian Institute of Health and Welfare 2014) and worldwide (United Nations Office on Drugs and Crime [UNODC] 2014) and is responsible for the majority of illicit drug apprehensions made by Australian law enforcement (Australian Crime Commission 2016). In Australia, the penalties applying to different cannabis supply offences are determined by quantity of harvested plant material and plants, and differ according to jurisdiction. While there has been regulatory change addressing penalties for possession use and cultivation in recent decades (see Room, Fischer, Hall, Lenton, and Reuter 2010), none of these have addressed issues of social supply. Further, we examine and theorise the concept of social supply through the lens of social capital.

Recent research has found drug markets to be highly culturally specific according to variables such as types of drugs sold, market type, ecological factors of the exchange, the socioeconomic backgrounds of seller and buyer, frequency of engagement with the market, the cultural context of the market, and the drug scenes to which it supplies (Murphy, Waldorf and Reinarman 1990; Coomber 2003; Jacinto, Duarte, Sales and Murphy 2008; Belackova, and Vaccaro 2013; Taylor and Potter 2013). In contrast to the stereotypes of drug markets as being hierarchical, top-down and prone to monopolisation (see Coomber 2010), most markets, especially those associated with cannabis, are typified by competition and independent distributors (Nicholas 2008). Australian research suggests that retail markets for most illicit drugs, including cannabis, are based significantly upon friendships and occur in closed and/or informal settings, which have been described as 'lounge room', as opposed to 'street' dealing (Lenton and Davidson 1999; AIHW 2014; Chanteloup, Lenton, Barratt, and Fetherston, 2005; Nicholas 2008; McDonald and Macgregor, 2012). Similar observations have been made in the United Kingdom (Coomber and Turnbull 2007), Europe (Belackova and Vaccaro 2013), the United States (Hamilton 2005) and New Zealand (Wilkins and Sweetsur 2006).

Most theories of drug use are underpinned by assumptions of illicit drug use as harmful, either to the user or society. Focussing on physical and psychological aspects of addiction has reinforced dominant pathology accounts of drug use and distracted from understanding the complex social dynamics of drug use. In particular, the contexts in which drugs are exchanged and social motivations for exchange have been variously obscured or simplified (Duff 2007). Similarly, stereotypes of drug distributers present them as existing outside of normal cultures and regulatory controls (Burgois1998; Karlsson 2010; Moore 2010). Social capital can draw attention to the diversity of drug supply networks and highlight the reciprocal nature of supply relations and unique forms of social organisation, which might be considered in terms of communities as opposed to markets.

An understanding of social capital may be useful in reframing illicit drug supply, as it recasts supply as socially motivated and embedded action, challenging the economic essentialism that has dominated popular and legal thinking around illicit drug supply. Further, with its emphasis on networks, norms and shared objectives, social capital assists in challenging an excessive individualism which has shaped the way we interpret drug supply, suggesting neither pathology or self-interest might alone account for motivations to supply. The supplier is not an autonomous agent who operates in a social vacuum, but is engaged in a range of varied social relationships, imbued with meaning.

Further, motivations for selling drugs are also highly variable. For example, the influence of peer pressure as a drug use initiator has been found to be often overemphasised and highly contextual, drug distribution is not always financially profitable and nor are distributors 
always motivated by financial profit (Murphy, Waldorf and Reinarman 1990; Potter 2009). In this way, recent research has supported earlier research from the 'new deviance' paradigm pioneered by Becker (1962) and Young (1971), which rejected the view of drug use and distribution as pathological and/or representative of social dysfunction and instead conceptualised it in terms of meaningful goal-oriented behaviour that exists within conventional value systems. Drug distribution is intimately related to social networks (Coomber and Turnbull 2007; Kandel and Davies 2006; Coomber 2010) and research suggests cannabis users are especially socially embedded (Osborne and Fogel 2008). While social networking theories have been used to understand deviance, research has typically focussed on organised crime networks or crime syndicates.

The term 'social supply' was coined to describe this aspect of the drug market, where a supplier, not considered to be a 'drug dealer proper', brokers, facilitates or sells drugs, for little or no financial gain to friends and acquaintances (Parker, Aldridge and Measham 1998). Social supply blurs the distinction between the retail level supplier and the end user (Hough, Warburton, Few, May, Man, Witton and Turnbull 2003). It also challenges stereotypical representations of drug supply to the extent that it is recast as non-predatory and noncommercially motivated (Coomber and Turnbull 2007). Much social supply that takes place between young people can be understood as part of everyday social network activities that involve brokering, sharing and facilitating access to a range of cultural goods and involvement is often as much about 'connecting' as it is about drug use per se (Coomber and Turnbull, 2007; Duffy, Schaefer, Coomber, O’Connell, and Turnbull, 2007).

The language of harm is interwoven with public perception and political and social responses to drug use. Because it is associated with relatively few social harms, social supply has implications for how we respond to the consumption and supply of drugs. Some have suggested that social supply should be defined in policy and law and distinguished from 'real' dealing (Coomber and Turnbull 2007; Duffy, Schaefer, Coomber, O'Connell and Turnbull 2007; Hough, Warburton, Few, May, Man, Witton and Turnbull 2003; Potter 2009). Users may be engaging in small-time selling to do friends a 'favour' or support their own drug use. Young drug users, often unwittingly, may be putting themselves at risk of a serious drug supply charge by engaging in activities which are seen by them as simply part of social exchange with peers (Nicholas, 2008). From a community perspective, even if the risk of apprehension is extremely low (About 2-3\% p.a. for any cannabis user) it has been shown that receiving a criminal charge for even a minor cannabis possession/use offence can have a devastating impact on those individuals who do get apprehended in terms of future employment prospects (Graffam, Shinkfield and Hardcastle 2008; Kilmer 2002), further attention from and involvement in the criminal justice system, accommodation, relationships and travel opportunities (e.g. Lenton 2000, 2005; Lenton and Heale 2000; Lenton, Humeniuk, Heale, and Christie 2000).

Due to the size and nature of the cannabis market in Australia, cannabis provides an opportunity to study the processes of social networks in which motivations for involvement are likely to be broader than simple profit or self-interest. We further theorise drug supply as socially motivated action, which might be best understood in terms of social capital, being a rational, informed and 'normalized' activity, as distinct from being pathological or socially dysfunctional. This framework has implications not only for how drug supply is regulated, but also how we understand drug associated harms.

\section{Social Capital}

In the modern era constructions of the 'pusher' reinforced distinctions between drug suppliers and users. The stereotype of the drug pusher was often that of an older male reprobate, who was anomic and, perhaps, sociopathic, being uncaring, untrustworthy, predatory and violent (Coomber 2010). In sum, the pusher was characterised as anti-social, but this failed to explain 
how much drug distribution relies on the ability of those who sell drugs to bridge diverse social networks. While it is not the purpose of this paper to evaluate social constructions such as 'pusher', the paper builds on an emerging body of research which seeks to understand drug supply in the context of the 'normalisation' of drug use, or as an everyday activity (see Parker, Aldridge and Measham 1998; South 1999; Shiner and Newburn 1999; Pearson 2001; Duff 2005; Measham and Shiner 2009; Aldridge, Measham and Williams 2011).

Social capital describes features of social organisation, such as relations of honesty, cooperation, reciprocity, engagement and mutual obligation (all described in this paper) that exist between people within social networks. It develops within groups and across groups (Putnam 1993). Drug distribution and consumption clearly occurs within social networks of varying size. Portes (2000) describes social capital as the ability of actors to receive benefits by virtue of membership of social networks. It is not something which resides in actors themselves, but a product of relations between them and facilitates coordinated, mutually beneficial outcomes for the collective (Rostila 2010). All social networks facilitate some form of social capital, but certain kinds of structure are especially important in creating social capital (Coleman 1988).

To understand drug supply in terms of social capital is not to completely disassociate the practice from a motivational context that might include profit or income generation. Rather, as defined in Bourdieu's (1986) work, social capital generates resources that can be used for economic, cultural (or informational) or symbolic benefit. In this way, social capital is used here to consist of the aggregate of resources, symbolic and material, that accrue to an individual or group by belonging to a durable network of mutual acquaintance and recognition (Wacquant 1998). Moving from older pathology or deviance frameworks for understanding drug supply, this definition makes it possible to understand drug supply as meaningful goal-oriented behaviour, which occurs in everyday contexts and is explicable with reference to conventional or mainstream norms. 'Success' as a drug supplier might be understood in terms of sustained involvement in the activity over a period of time, which is itself explicable with reference to economic, social and cultural forms of capital. Success as a drug supplier may have more in common (e.g. organisational skills, specialist knowledge, perseverance, planning, determination, managing relationships etc.) with success other successful (social) activities, than it does with deviance. In this respect, it is unhelpful to conceive drug suppliers as deviant or anti-social,, as such a conceptualisation fails to account for motivations for this activity or the capacity to successfully participate in this activity, which requires, as shown below, capacity for social integration.

The above noted, the term social capital, as it is used here, describes networks of varying density. Not all, for example, can be described as 'closed'. The significance of brokerage in social supply, for example, suggests the operation of looser drug distribution networks.

Putnam (1993) has discussed the relative density of social networks with reference to bonding and bridging ties. Wacquant (2012), drawing on Bourdieu (1986), has also described formal and informal social capital. Bonding ties are evident in closed and intimate groups in which all members are connected and interact exclusively with one another. Bonding ties are inward looking and occur amongst people who see themselves as coming from same social network (Rostila 2010). Weaker ties may be typical of the social contacts and acquaintances described in the context of social supply as such ties are less likely to be based on close or enduring bonds of kinship or close stratification, but develop between diverse communities. However, these weak ties provide links to wider social circles and it has also been suggested weaker ties facilitate access to information beneficial to networks (Rostila 2010). Warr (2005) and Barker (2012), for example, suggest that bridging capital can assist in the development of economic capital and also provide resistance to stigma which can be compounded by diminished or limited social networks. Indeed, social capital may enhance our understanding of processes of normalisation associated with drug use and supply. 


\section{Method}

Cannabis users aged between 18 and 30 years were recruited in three project sites. Eighty participants were recruited in both Perth and Melbourne and 40 in Armidale (New South Wales). These sites were chosen because they provided diverse contexts, comprising a large and mid-sized Australian capital city and a medium sized regional centre. Participants must have used cannabis at least monthly in the three months prior to interview, and/or had brokered access to or sold cannabis within the six months prior to interview. Participants were recruited using snowball sampling, which incorporated mainstream street press, flyers and a project website.

The median age of the sample was 22 years and $71 \%$ were male. The majority of the sample $(60 \%)$ described an Australian or New Zealand ethnicity followed by North West European (27\%). Only $1 \%$ identified as being Indigenous background. The participants were generally well-educated for their age, with $61 \%$ of the sample reporting the completion of a tertiary qualification. Some $55 \%$ cited employment as their main income source, $26 \%$ pension or allowances, $12 \%$ family, and only $4 \%$ said the sale of drugs was their main income stream. Some 54\% reported residing in rental accommodation and 32\% in the parental home.

Participants were reimbursed $\$ 40$ for attending the face-to-face interviews, which utilized a structured questionnaire, with both quantitative and qualitative components, and took 1-2 hours to complete. The interviews and questionnaire included questions on demographics, experience of cannabis and other drug use; accessing cannabis, selling or brokering access to cannabis; police contact regarding cannabis, and knowledge of cannabis laws. Qualitative data were digitally recorded for transcription and analysis. Qualitative information was transcribed by Pacific Transcription and analysed using NVivo 10 (QSR International Pty Ltd., 2006). Quantitative data was analysed using SPSS (SPSS Inc., 2003) and STATA. The project was approved by Human Research Ethics Committees at both Curtin University (HR 172/2011) and The University of New England (HE12-155).

For the purpose of the analysis, a 'dealer' was defined as a person who was known to sell cannabis, whereas a 'stranger' was someone they had obtained cannabis from, but knew nothing about (i.e. an opportunistic encounter). 'Obtaining' cannabis was defined as an occasion where participants purchased it, grew it, or were given it, where it became their property. This practice was differentiated from simply 'sharing' cannabis with someone at a social gathering. Following Duffy, Schaefer, Coomber, O'Connell and Turnbull (2007), we define a drug seller as a person who sells cannabis for money or other goods, noting that whilst some primarily sell for financial profit, others sell for other material gains or to fund their own use. We use the term broker for a person who, primarily for altruistic reasons, helps friends or acquaintances gain access to cannabis (from passing on details of a seller to actually buying cannabis on the person's behalf). Brokering does not result in financial gain, but the broker may receive a small amount of cannabis for their activities.

\section{Results}

Almost the entire sample $(94 \%, \mathrm{n}=188)$ reported supplying cannabis at some point in their lifetime, whether it be giving, brokering, swapping or selling. Some $83 \%(n=156)$ of those who reported that they had ever supplied cannabis had also done so in the past 6 months and $64 \%(n=120)$ had done so during the past month. Recent suppliers reported supplying for a median of two years.

The median number of people that participants reported currently supplying cannabis to was four (interquartile range $=3-8$ people). The median age at which participants reported first supplying cannabis was 17 years old (interquartile range $=16-18$ years). 
Participants who had supplied cannabis in the past month said the median amount of cannabis supplied in a typical week was three grams (interquartile range $=1-7$ grams) and the median amount that cannabis was sold for in a typical week was $\$ 45$ (interquartile range $=\$ 19-\$ 100$ ).

Results for obtaining cannabis differed little from supply. Overall, participants obtained their cannabis from a median of three different people. Participants reported obtaining cannabis from their main supplier for a median of a year, suggesting a sustained relationship with their supplier. Almost all participants reported that cannabis was either 'very easy' $(56 \%, \mathrm{n}=112)$ or 'easy' $(36 \%, \mathrm{n}=71)$ to obtain. The median amount obtained in a typical transaction was 3.5 grams (i.e., one-eighth of an ounce) and the median amount paid per transaction was $\$ 50$ (interquartile range $=\$ 12.50-\$ 75$ ).

The median age of the person participants reported mainly obtaining their cannabis from was 25 years old (interquartile range $=21-28$ years). The median age difference between participants and their main supplier was two years. Overall, the profile of suppliers differed very little from those who they supplied and this seems to have provided opportunities for social exchanges, as we discuss below.

\section{Motivations for Selling}

Of those who had supplied, the majority $(65 \%, \mathrm{n}=122)$ reported that the best statement to describe what they had ever done was 'I supply cannabis only to friends/family' or 'I supply cannabis only to friends/family and their friends'. Only a small proportion $(13 \%, n=24)$ reported 'I supply to anyone willing to buy, including strangers'. One participant presented drug supply in terms of providing 'help' to others within a mutually supportive social network, observing:

We understand each other and if one person is in need we help them out. If any of us has access and others don't, we will all help each other.

[P09, male, 20yrs]

The majority of people who brokered or sold did not report that they were chiefly concerned with making a profit. Reciprocity was often emphasised by participants. As one cannabis supplier stated:

Basically I just like people to - if I don't have weed [cannabis] it would be really cool if someone could help me out and then I repay them so I do the exact same thing when they don't have any [P54, male, 19yrs]

Of those who had supplied, the greatest proportion $(41 \%, n=77)$ reported that the statement that best described the nature of their involvement in cannabis supply ever was 'I supply for the same price as originally purchased (brokering)'; followed by 'I supply for profit that covers some or all of my use' $(21 \%, n=39)$ and then 'I supply for profit that covers my use plus a little extra' $(19 \%, n=35)$. Only $16 \%(n=30)$ reported that the statement best describing their involvement in cannabis supply as 'I supply for profit that covers my use plus significant profit'.

The relationship between the supplier and those supplied was a major factor in determining pricing. Over a quarter of the participants suggested that friends received preferential treatment, while only a handful of participants said that they charged the same price 
regardless of relationship. A normative structure, based on notions of 'help' and friendship, guided the legitimacy of making a profit from cannabis supply. One participant said:

I find I wouldn't make profit unless it was - I didn't know the person directly. If it was his friend was like hey, if his friend asked him to get some and then he asked me I'dI might make a small amount of profit. I generally feel bad about that and if it's friends that I know I'm not in it for profit, I just want to help them out [M18, male, $24 \mathrm{yrs}]$.

It was clear from the data that suppliers and those they supplied shared common norms and objectives, mostly constructed around notions of sociality and reciprocity. As suggested in the quote above, many participants who brokered for others did not charge an additional amount over and above the cost price. Similarly, many who sold cannabis would sell it at market value, and some even gave their friends a good deal to their own disadvantage. In this way, investing time and energy socially could influence or determine the price of cannabis and levels of profitability. Exploration of qualitative data revealed that there was not a great deal of variation in attitudes towards supplying across the age groups. The most significant difference was that older participants were more likely to supply for no gain, share and gift cannabis, and were more likely to discuss morals, ethics and cannabis culture. There were several cases of participants feeling that their attitudes towards cannabis had changed since they were younger, stating that with age they became more casual in their approach towards cannabis use and supply.

\section{Obtaining Cannabis}

The three most commonly reported ways participants came into contact with their main supplier could be broadly recoded into the following categories; 'social network/friends-offriends' $(45 \%, \mathrm{n}=89)$, 'school' $(16 \%, \mathrm{n}=32)$ and 'intermediary link up to dealer via friend' $(12 \%, n=24)$. Further exploration of responses found that one-quarter of the sample $(25 \%$, $\mathrm{n}=50$ ) reported that since obtaining cannabis from the seller, a friendship had either evolved or strengthened. As indicated in the quote below, friendships could emerge from supply relationships:

I like some of my dealers, I've actually become friends with them, through buying off them. Some people - I've got one friend and his room is in a garage at the side of his house - you can just go there whenever and he's like a really, really nice person [P58, female, 18yrs].

Participants were asked to explain how well they knew the main person they obtain cannabis from, including what the nature of their relationship was. An exploration of open-ended responses revealed that the majority of participants $(65 \%, \mathrm{n}=129)$ reported that they were either 'close friends' $(34 \%, n=66)$ or 'friends' $(32 \%, n=63)$ with their main supplier. Less than one-quarter of the sample $(18 \%, n=36)$ reported that the relationship with their main supplier was 'strictly business'. Overall this suggests that for about three quarters or more of the cases, those main suppliers who were currently viewed as 'friends', started as 'friends', and those who were currently viewed as 'dealers' were initially viewed as 'dealers'. There were few reports of violence, threats of violence or stand-over tactics being experienced by research participants describing their involvement in these cannabis transactions. While there were reports of uncomfortable situations, these did not involve violence or threats of violence. This may partly be a factor of the relatively small amounts being exchanged in addition to motivational factors involved in the exchange. 
Overall, exchanges with friends tended to be a lot more informal and often occurred in relaxed, social settings, typically the home of the supplier or buyer. The expression 'killing two birds with one stone' was quoted on several occasions, suggesting that the interaction involved both social interaction and obtaining the cannabis, although the relative importance of these functions varied between people and occasions. The reciprocal nature of the exchange and sociality was regularly emphasized by participants, who drew contrasts to business exchanges. As a participant stated:

I call my guy up who's also my bro; meet up with him and pay money, you know, pay money, receive goods and that's it. Maybe I might chill out with him for a while and sample the product together. I don't know; it's very much a social thing. Like, it's not like a business where you just pay money and receive product. Like, you use it with him, like, he owes you some, so next time you see him he gives you a good deal, like, to pay back the stuff that he took from you before, or vice versa and so on and so forth [P39, male, 27yrs].

As reflected above, participants regularly suggested that social investment was likely to improve the quality of the exchange and product exchanged. People involved in drug exchanges gain more from the interaction than just drugs..

\section{Identifying as a Cannabis Supplier}

Qualitative data indicated that roughly three-quarters of participants who had supplied cannabis in the last 6 months did not identify as drug dealers. As the data in this section indicates, 'dealing' drugs was constructed as an anti-social and socially harmful activity by some participants, especially if it was primarily motivated by profit. Some were taken aback by the seeming accusation that they were drug dealers. Others said they had never previously reflected on their status. In terms of defining their own supply activities, some participants did not consider themselves dealers because they supplied only to friends, did not consider cannabis to be a drug, and/or did not supply regularly. A participant observed:

I'm not making any profit and I've only done it a few times and only to people that I'm very close friends with, whereas - I don't know, that doesn't really fit what I think of as a dealer anyway [P36, male, 24yrs].

Of those that did view themselves as dealers, the most common reason for doing so was that they dealt 'drugs' by definition, or considered that making a profit meant they were dealers. Over a third of participants defined a drug dealer as someone who made a financial profit from the sale of drugs. By implication or overtly, non-dealers were clandestine or 'amateur', socially motivated and eschewed a profit motive. Sociality was again emphasised by a participant who stated:

They don't seem to make their main goal, this activity. They don't keep an overly large amount. The guy works at other jobs. It's kind of just showing up in the afternoon, hanging out there for a bit because he's just finished work and he always wants to have a chat and things. I think he does it more as a social thing because he seems to be the kind of person that doesn't overly have friends and stuff, works a nine to five job and kind of it seems to be selling is more of a social activity for him than actually making money [A16, male, 18yrs].

A small number of participants thought that dealers were people who supplied cannabis to people other than friends or strangers. One participant contrasted a client relationship with that of friendship: 
I'd see them [dealers] more as having kind of clients, rather than friends. Certainly, when I've bought off dealers in the past, it's like a situation - don't go in the house. You knock on the door. Maybe there's a special word you use on the phone. There's all this stuff. It's like a whole charade [M81, female, 26yrs].

Over a quarter of participants defined drug dealers in a negative fashion, as someone 'dodgy', criminal, untrustworthy, or likely to deceive them. A participant viewed drug dealers as anomic, suggesting them to be:

Somebody who has no morals, no compassion and no thought or care for anybody else's safety, health, family, any problems. A drug dealer is somebody who sells things that are known to be harmful and very destructive to people and does it without a care, completely for their own profit, or because they're addicted themselves and they need it to feed their addiction. That's what a drug dealer is [A31, female, 21yrs].

Drug dealers were considered self-interested, untrustworthy and asocial, whereas the social supply relationship drew on trust, which allowed for it to be conceived in terms of 'friendship' and contrasted with the 'public' world of business.

\section{Discussion}

The representations of cannabis market activities used by most participants in this study, whether they be involved in obtaining or supplying cannabis, could be captured by of the notion of social supply, where a supplier, not considered to be a 'drug dealer proper', brokers, facilitates or sells drugs, for little or no financial gain to friends and acquaintances. The concept of social supply is useful to understand the dynamics of drug markets to the extent that it highlights motivations for drug distribution. To the extent that it relates to the lower level supply, it suggests the primary motivation for drug supply and use is to accrue social capital, not financial capital. This point is significant and allows for some further theorisation of the concept of social supply, often absent from the literature. Still, as the data above suggests, social capital plays a key element in determining pricing in drug markets and, so, may be a useful concept even in circumstances in which social supply is not a dominant mode of distribution.

It is notable that almost the entire sample reported supplying cannabis to another person at some point in their lifetime, whether it be giving, brokering, swapping or selling. While the normalization thesis (see Parker, Aldridge and Measham 1998; South 1999; Pearson 2001; Duff 2005) posits drug use as a mainstream as opposed to deviant activity, problematising the dichotomy between user and non-user, this finding suggests that the distinction between supplier and user may also be questionable in describing some forms of drug distribution and that drug supply itself, particularly at a 'lower-level', should be also seen as a normalized activity. It makes questionable assertions that drug suppliers are different from users or wield excessive power in exchange interactions. Instead, social capital highlights the reciprocal nature of supply interactions. Certainly there was little to distinguish either group demographically. This noted, the potency of the pusher myth was evident in the way participants understood the stigmatization of the supply of drugs in the broader social context and how this impacted on the way they considered their own drug related activities. Certainly the idea of cannabis markets as profit driven and violent is partially premised on the notion that dealing is a male dominated practice, but our sample, approximately 30 per cent of who were women, challenges this assumption. Also notable is the relatively small amounts of 
cannabis exchanged, which runs counter to popular imagery in police television shows and drug busts in news media, which highlight large, elaborate forms of supply which contrasts to the market described here which is characterised by 'low level' exchanges between 'friends'. Nonetheless, drug policy clearly targets the higher end of the market, despite ultimately widening the policing net to include the smaller level suppliers described here. In the UK in particular, there has been extensive consideration of whether such 'low-level' drug offences should be dealt with differently in law than 'drug dealing proper' (Home Affairs Committee 2002).

Most people who engaged in supply did not consider themselves to be 'a dealer'. This also underscores the argument that interpretations of drug use are not just imposed on users and the wider public by external discourses and authorities, but are also produced through complex processes of self-definition which are contingent on a range of individual and structural contexts and conditions, which include cultures or communities of drug use (see Pereira 2013). One way of thinking about social supply is that this kind of drug supply market could 'morally sanitise' the view that participants' have of their own behaviour as consumers and/or suppliers (Nicholas 2008; Potter 2009). Indeed, the avoidance of the label, given the stigma cited above, may be a method of deviance neutralization (see Sykes and Matza 1957) or stigma management (Goffman 1963). This noted, the construction of self as normative required not only avoidance and disavowal of the dealer label, but also involved a counterconstruction of the self as social and altruistic and/or ethical. This may explain how forms of bridging capital or contact with diverse communities, may operate to produce an identity or sense of self as 'normal' or a sense of belonging defined in terms of shared cultural values and norms.

Much of the research literature on social capital assumes a consensus perspective that aligns 'the common good' with mainstream or official functions of social control. As such, social capital facilitates crime control, rather than facilitating criminal or deviant activity. Social capital, in the form of collective efficacy, has been linked to crime prevention, especially with respect to violent crime (Sampson, Raudenbush and Earls 1997; Kennedy, Kawachi, Prothrow-Smith and Lochner 1998; Buonnnano, Montolio and Vanin 2009). In a similar vein, social capital has been frequently associated with prevention or reduction of deviant (risk) health behaviours such as alcohol and tobacco use (Lindstrom 2003; Weitzman and Chen 2005; Reynoso-Vallejo 2015). Lindstrom (2004), for example, argued that anti-social values, such as low generalised trust of others, and beliefs are positively associated with cannabis use. This contrasts sharply with the data presented here and recent research by ReynososVellejo (2015), which found an association between social capital, such as trust and norms of reciprocity, and drug use.

On a broad level, it may be said that many activities designated as illegal or deviant generate social capital. This is particularly true of activities which involve criminal gangs or subcultures and certain types of so-called 'victimless crimes'. As is clear from the data presented here, drug use occurs in a highly normative setting and individuals understand their use of drugs in the context of shared values and norms. It is also clear that drug networks regulate their activities and that much of this regulation draws on conventional or mainstream values and norms for its veracity. Our participants, for example, drew a clear distinction made between 'dealing' and social supply, the former being clearly deviant and asocial. And while our participants may not have emphasised economic capital as a primary motivational factor in their interactions, social networks clearly provided participants with access to economic and cultural capital, in addition to social capital (see Barker 2012). The number of participants who broker or use intermediaries to access cannabis provides a vivid illustration of bridging forms of social capital at work. 
Social capital is a product of legal status of drugs to the extent that behavioural norms and cues based on friendship compensate for risks in the market, and are likely to apply more in places where drug use is regarded as deviant or criminal and drug related activity is subject to policing and sanctions (Belackova and Vaccaro 2013). For all members of a social supply network, norms of friendship and trust are mutually beneficial, especially in an unregulated market, where, as noted above, they allow for sellers and users to avoid official surveillance and sanctions (Taylor and Potter 2013; Coleman 1988; Belackova, and Vaccaro 2013). Drug networks have previously been found to be socially 'functional' to the extent that they help enforce informal norms of personal safety, health, product quality, price and availability. Informal social controls are, in such instances, used to maintain and regulate social networks in absence of formal ones (Wilkins 2001; Williamson 2000). Social ties can reduce the risk of being sold poor quality drugs, being reported to police or being a victim of associated criminal activities, such as theft of goods. Nicholas (2008) has canvassed potential harms that could result from the disruption of social supply networks by police, such as increased activity in open (street) markets that are associated with higher levels of criminality, violence and negative impacts on public amenities. A possibility is that social supply as a form of drug distribution is actually less harmful than a market that might replace it (also noted by Nicholas, 2008; Sutton and James, 1996). Known sellers or brokers seem to provide shielding between end consumers and more harmful/criminal players in the market. Framing this 'functionality' in terms of social capital extends the concept of social supply by couching drug supply relationships in terms of socially embedded and motivated action.

Finally, the concept of social capital is intimately linked with the notion of community in sociology. Community-like relations can be found in networks of varying size and exist in diverse physical spaces. This research indicates that drug distribution networks resemble community structures to the extent that it may be appropriate to speak of drug using communities, as opposed to markets, in describing such networks. That noted, sociology has also done much to indicate a diverse range of communities, including natural and elective, imagined and virtual (Brint 2001). A social understanding of drug cultures should be couched in a framework of community structures. A new direction in research, extending of the concept of social supply, might document different types of drug communities (including the motives underlying social relations) and the impact that such communities have on both social harm and well-being.

\section{Funding}

This project was supported by a grant from the Australian Government Department of Health and Ageing through the National Drug Law Enforcement Research Fund (NDLERF).

The National Drug Research Institute in the Faculty of Health Sciences at Curtin University and the National Drug and Alcohol Research Centre at UNSW Australia are supported by funding from the Australian Government under the Substance Misuse Prevention and Service Improvement Grants Fund. JG, SL and MB were supported from this source through their employment at these institutions. MB is also the recipient of a National Health \& Medical Research Council Early Career Researcher Fellowship (APP1070140). MB gratefully acknowledges the contribution to this work of the Victorian Operational Infrastructure Support Program received by the Burnet Institute.

\section{REFERENCES}

Aldridge, J. F. Measham and L. Williams (2011) Illegal Leisure Revisited: Changing Patterns of Alcohol and Drug Use in Adolescents and Young Adults. London: Routledge. 
Australian Crime Commission (2014) Illicit Drug Data Report 2012-13. Canberra: Australian Crime Commission.

Australian Institute of Health and Welfare (2014) 2013 National Drug Strategy Household Survey: Detailed Findings. Canberra: Australian Institute of Health \& Welfare.

Barker, J. (2012) 'Social Capital, Homeless Young People and the Family', Journal of Youth Studies, 15: 730-43.

Becker, H. (1963) The Outsiders: Studies in the Sociology of Deviance. New York: The Free Press.

Belackova, V. and C. Vaccaro. (2013) “"A Friend with Weed is a Friend Indeed”:

Understanding the Relationship Between Identity and Market Relations Among Marijuana Users', Journal of Drug Issues 43: 289-313.

Bourdieu, P. (1986) 'The Forms of Capital', pp. 241-258 in J. Richardson (ed.) Handbook of Research and theory for Sociology of Education. New York: Greenwood Press.

Bourgois, P. (1998) 'Just Another Night in the Shooting Gallery', Theory, Culture and Society 15: 37-66.

Brint, S. (2001) 'Gemeinschaft Revisited: A Critique and Reconstruction of the Community Concept', Sociological Theory 19: 1-23.

Buonnnano, P. D. Montolio and P. Vanin (2009) 'Does Social Capital Reduce Crime?', Journal of Law and Economics 52: 145-70.

Chanteloup, F. S. Lenton, M. Barratt and J. Fetherston (2005) Effects of the Western Australian Cannabis Infringement Notice Scheme on Regular Cannabis Users Regarding Attitudes, Use and Drug Market Factors - Baseline, Year 1. Perth: National Drug Research Institute, Curtin University of Technology.

Coomber, R. (2003) 'There's No Such Thing as a Free Lunch: How "Freebies" and "Credit" Operate as Part of Rational Drug Market Activity', Journal of Drug Issues 33: 939-62.

Coomber, R. and P. Turnbull (2007) 'Arenas of Drug Transactions: Adolescent Cannabis Transactions in England - Social Supply’, Journal of Drug Issues 22: 1-22.

Coomber, R. (2010) 'Reconceptualising Drug Markets and Drug Dealers - The Need for Change', Drugs and Alcohol Today 10: 10-3.

Coleman, J. (1988) 'Social Capital in the Creation of Human Capital', The American Journal of Sociology 94: 95-120.

Duff, C. (2005) 'Party Drugs and People: Examining the 'Normalization of Recreational Drug Use in Melbourne, Australia', International Journal of Drug Policy 16: 161-70.

Duff, C. (2007) 'Towards a Theory of Drug Use Contexts: Space, Embodiment and Practice', Addiction Research and Theory 15: 503-19.

Goffman, E. (1963) Stigma. London: Penguin. 
Graffam, J. A.J. Shinkfield and L. Hardcastle (2008). 'The Perceived Employability of Exprisoners and Offenders', International Journal of Offender Therapy and Comparative Criminology 52: 673-85.

Hamilton, J. (2005) 'Receiving Marijuana and Cocaine as Gifts and Through Sharing', Substance Use and Misuse 40: 361-8.

Home Affairs Committee (UK) (2002) The Government's Drugs Policy: Is It Working? London: House of Commons (URL: http://www.archive2.officialdocuments.co.uk/document/cm55/5573/5573.pdf) Accessed 14 June 2011).

Hough, M. H. Warburton, B. Few, T. May, L.-H. Man, J. Witton and P. Turnbull (2003) A Growing Market: The Domestic Cultivation of Marijuana. York: Joseph Rowntree Foundation.

Jacinto, C. M. Duarte, P. Sales and S. Murphy (2008) 'I'm Not a Drug Dealer: The Identity Process of Ecstasy Users', Journal of Drug Issues 38: 419-44.

Kandel, D. and M. Davies (2006). 'Friendship Networks, Intimacy, and Illicit Drug Use in Young Adulthood: A Comparison of Two Competing Theories', Criminology 29: 441-69.

Karlsson, P. (2010) 'Alternatives to the Deficit Model of Adolescent Drug Use', pp. 21-34 in T. Decorte and J. Fountain (eds.), Pleasure, Pain and Profit: European Perspectives on Drugs. Lengerich, Germany: Pabst Science Publishers.

Kennedy, B. I. Kawachi, D. Prothrow-Smith and I. Lochner (1998) 'Social Capital, Income Inequality and Firearm Violent Crime’, Social Science and Medicine 47: 7-17.

Kilmer, B. (2002) Do Cannabis Possession Laws Influence Cannabis Use? Cannabis 2002 report - Technical Report of the International Scientific Conference, Brussels, Belgium. (pp. 101-23). Brussels: Ministry of Public Health of Belgium.

Lindstrom, M. (2003) 'Social Capital and the Miniaturization of Community Among Daily and Intermittent Smokers: A Population Based Study’, Preventative Medicine 36, 177-84.

Lindstrom, M. (2004) 'Social Capital, the Miniaturization of Community and Cannabis Smoking Among Young Adults', European Journal of Public Health 14: 204-8.

Lenton, S., and P. Davidson (1999) 'Raves, Drugs, Dealing and Driving: Qualitative Data from a West Australian Sample’, Drug and Alcohol Review 18: 153-61.

Lenton, S. (2000) 'Cannabis Policy and the Burden of Proof: Is it Now Beyond Reasonable Doubt that Cannabis Prohibition is not Working?', Drug and Alcohol Review 19: 95-100.

Lenton, S. (2005) 'Evaluation of the WA Cannabis Infringement Notice Scheme - An Overview', Drug and Alcohol Review 24: 297-9.

Lenton, S., and P. Heale (2000) 'Arrest, Court and Social Impacts of Conviction for a Minor Cannabis Offence Under Strict Prohibition', Contemporary Drug Problems 27: 805-33.

Lenton, S. R. Humeniuk, P. Heale and P. Christie (2000) 'Infringement Versus conviction: The Social Impact of a Minor Cannabis Offence in SA and WA', Drug and Alcohol Review 19: 257-64. 
McDonald, H. and S. Macgregor (2012) Bulletin 10: Cannabis Use and Market Indicators: A Comparison Between Detainees from Australia and the United States. Canberra: Australian Institute of Criminology.

Measham, F. and M. Shiner. (2009) 'The Legacy of "Normalization": The Role of Classical and Contemporary Criminological Theory in Understanding Young People's Drug Use', International Journal of Drug Policy 20: 502-8.

Moore, D. (2010). 'Beyond Disorder, Danger, Incompetence and Ignorance: Rethinking the Youthful Subject of Alcohol and Other Drug Policy', Contemporary Drug Problems 37: 47598.

Murphy, S. D. Waldorf and C. Reinarman (1990) 'Drifting into Dealing: Becoming a Cocaine Seller', Qualitative Sociology 13: 321-43.

Nicholas, R. (2008) The Impact of Social Networks and Not-for-profit Illicit Drug Dealing on Illicit Drug Markets in Australia - A Discussion Paper, Hobart: National Drug Law Enforcement Research Fund.

Osborne, G. B. and C. Fogel (2008) 'Understanding the Motivations for Recreational Marijuana Use Among Adult Canadians', Substance Use \& Misuse 43: 539-72.

Parker, H. J. Aldridge and F. Measham (1998) Illegal Leisure: The Normalization of Adolescent Recreational Drug Use. London: Routledge.

Pearson, G. (2001) 'Normal Drug Use: Ethnographic Fieldwork Among an Adult Network of Recreational Drug Users in Inner London', Substance Use \& Misuse 36: 167-200.

Pereira, M. (2013) Governing Drug Use Among Young People: Crime, Harm and Contemporary Drug Use Practices. [unpublished thesis], Brisbane: Faculty of Law, Queensland University of Technology.

Potter, G. R. (2009) 'Exploring Retail-level Drug Distribution: Social Supply, 'Real' Dealers and the User/dealer Interface' pp. 50-74 in Z. Demetrovics, J. Fountain \& L. Kraus (eds.), Old and New Policies, Theories, Research Methods and Drug Users Across Europe. Germany: Langerich.

Portes, A. (2000) 'The two meanings of social capital', Sociological Forum 15: 1-12.

Putnam, R. (1993) Making Democracy Work: Civic Traditions in Modern Italy. Princeton, NJ: Princeton University Press.

QSR International Pty Ltd. (2012). NVivo qualitative data analysis software (Version 10).

Reynoso-Vallejo, H. (2015) 'Social Capital Influence in Illicit Drug Use Among Racial/Ethnic Groups in the United States', Journal of Ethnicity in Substance Abuse 10: 91111.

Rostila, M. (2010) 'The Facets of Social Capital', Journal for the Theory of Social Behaviour 41: 308-326.

Room, R. B. Fischer, W. Hall, S. Lenton and P. Reuter (2008) The Global Cannabis Commission Report: Cannabis Policy - Moving Beyond Stalemate. The Beckley Foundation, Oxford. Available at http://www.beckleyfoundation.org/pdf/BF_Cannabis_Commission_Report.pdf. 
Sampson, R. S. Raudenbush and F. Earls (1997) 'Neighbourhoods and Violent Crime: A Multilevel Study of Collective Efficacy’, Science 227: 918-24.

Shiner, M. and T. Newburn. (1999) 'Taking Tea with Noel: The Place and Meaning of Drug Use in Everyday Life' pp. 140-60 in N. South (ed.) Drugs: Cultures, Controls and Everyday Life. London: Sage.

South, N. (1999) 'Debating Drugs and Everyday Life: Normalization, Prohibition and "Otherness"” pp. 2-17 in N. South (ed.) Drugs: Cultures, Controls and Everyday Life. London: Sage.

Sykes, G. and D. Matza (1957) 'Techniques of Neutralization: A Theory of Delinquency', American Sociological Review December, 664-70.

Taylor, M. and G. Potter (2013) 'From Social Supply to 'Real Dealing': Drift Friendship and Trust in Drug Dealing Careers', Journal of Drug Issues 43: 392-406.

United Nations Office on Drugs and Crime (UNODC) (2014) World Drug Report 2014. New York: United Nations.

Wacquant, L. (1998) 'Negative Social Capital: State Breakdown and Social Destitution in America's Urban Core'. Netherlands Journal of Housing and Built Environment 13: 25-40.

Warr, D. (2005) 'Social Networks in a discredited neighbourhood', Journal of Sociology 41: 235-308.

Weitzman, E. and Y. Chen (2004). 'Risk Modifying Effect of Social Capital on Measures of Heavy Alcohol Consumption, Alcohol Abuse, Harms and Second-hand Effects: National Survey Findings', Journal of Epidemiology and Community Health 59, 303-309.

Wilkins, C. and P. Sweetsur (2006). ' Exploring the Structure of the Illegal Market for Cannabis', De Economist 154: 547-62.

Wilkins C. (2001) 'New Institutional Economics Approach to the Reliability of Street-Level Drug Transactions', Contemporary Drug Problems 28: 679-93.

Williamson O. E. (2000) 'The New Institutional Economics: Taking Stock, Looking Ahead', Journal of Economic Literature, XXXVIII: 595-613.

Young, J. (1971) The Drug Takers: The Social Meanings of Drug Use. London: Paladin. 